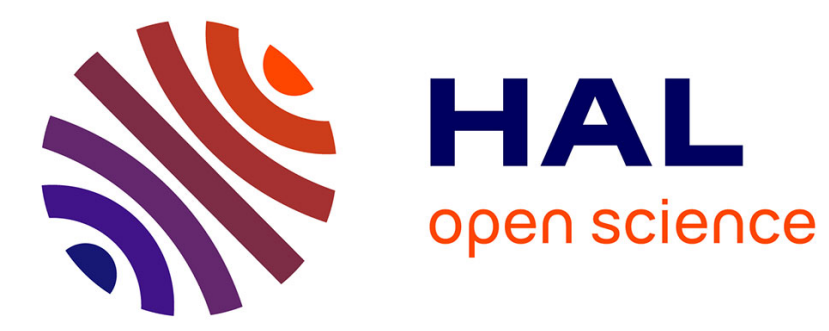

\title{
Modeling mixed fermentation of gowé using selected Lactobacillus plantarum and Pichia kluyveri strains
}

Christian Mestres, Bettencourt de J.C. Munanga, Joël Grabulos, Gérard Loiseau

\section{- To cite this version:}

Christian Mestres, Bettencourt de J.C. Munanga, Joël Grabulos, Gérard Loiseau. Modeling mixed fermentation of gowé using selected Lactobacillus plantarum and Pichia kluyveri strains. Food Microbiology, 2019, 84, pp.103242 -. 10.1016/j.fm.2019.103242 . hal-03485664

\section{HAL Id: hal-03485664 \\ https://hal.science/hal-03485664}

Submitted on 20 Dec 2021

HAL is a multi-disciplinary open access archive for the deposit and dissemination of scientific research documents, whether they are published or not. The documents may come from teaching and research institutions in France or abroad, or from public or private research centers.
L'archive ouverte pluridisciplinaire HAL, est destinée au dépôt et à la diffusion de documents scientifiques de niveau recherche, publiés ou non, émanant des établissements d'enseignement et de recherche français ou étrangers, des laboratoires publics ou privés.

\section{(ㅇ)(1) $\$$}

Distributed under a Creative Commons Attribution - NonCommerciall 4.0 International 
1 Modeling mixed fermentation of Gowé using selected Lactobacillus plantarum

2 and Pichia kluyveri strains

3 Christian MESTRES ${ }^{1 *}$, Bettencourt de J. C. MUNANGA ${ }^{1,2}$, Joël GRABULOS ${ }^{1}$, Gérard

4 LOISEAU ${ }^{3}$.

51 CIRAD, UMR Qualisud, F-34398 Montpellier, France.

6 Qualisud, Univ Montpellier, CIRAD, Montpellier SupAgro, Université d'Avignon, Université de La Réunion, Montpellier, France. Cangambo, Malanje -Angola ; kudymwena@yahoo.com.br

3 Qualisud, CIRAD, Montpellier SupAgro, Univ Avignon, Univ Guyane, Univ

* Correspondance: Christian.mestres@ cirad.fr 31

\section{Abstract}

This paper describes a mixed fermentation model made by assembling block hosting models for the growth of lactic acid bacteria (Lactobacillus plantarum) and a yeast strain (Pichia kluyveri), metabolic production and the physical-chemical changes which occur during the fermentation of gowé. The growth model for P. kluyveri was developed on a synthetic medium following the gamma concept taking into account the effect of $\mathrm{pH}$, temperature, concentrations in glucose, lactic acid and ethanol. Additional parameters for the previously defined $L$. plantarum growth model were also determined (glucose and ethanol concentrations). The model was validated in three different gowé processing conditions. Even if the model underestimates LAB growth, it explains what occurs in the product and enables in silico extrapolation to various fermentation conditions. The predicted hydrolysis rates of native and gelatinised starches showed that increasing malt content is not an efficient way to increase the sweetness of gowé in contrast to increasing the level of pre-cooking. The builing-block model developed in this study could be applied to many other fermented foods and particularly to nonalcoholic but acid and sweet cereal based beverages.

Key words: Fermentation, Starter, Modelling, Lactobacillus, Pichia kluyveri, Saccharification. 


\section{Introduction}

33 Gowé is an indigenous sorghum based sour beverage produced by spontaneous fermentation typically resulting from the growth of mixed cultures of lactic acid bacteria (LAB) and yeasts (Adinsi et al., 2015; Akissoé et al., 2015). Mixed fermentation occurs in many fermented food in addition to gowé such as sour bread, non-alcoholic but acid and sweet beverages like boza made from millet in Eastern Europe and Turkey, mahewu from maize in southern Africa (Blandino et al., 2003) or cacao. It involve more than one microbial strain in interaction with others. Many different types of interactions are possible between microbial populations, but commensalism or mutualism is often observed when yeasts and lactic acid bacteria are involved in mixed fermentation. Yeasts can synthesise and release substances including vitamins, amino acids and purines, and break down complex carbohydrates, which are essential for the growth of lactobacilli species (Arroyo-López et al., 2008). Yeast species such as Debaryomyces hansenii and Yarrowia lipolytica assimilate the lactic acid formed by lactic acid bacteria, raising the $\mathrm{pH}$ and stimulating bacterial growth. In return, $\mathrm{LAB}$ produce lactic acid that lowers the $\mathrm{pH}$, either inhibiting the growth of undesirable pathogens and/or promoting yeast growth (Nout $e t$ al., 1989; Nout, 1991; Viljoen, 2006).

Two types of mathematical models are used to study the behaviour of a mixed fermentation; those only based on the growth curves of the species concerned and those which account for the mechanisms underlying the interaction (decrease in $\mathrm{pH}$, consumption of limiting substrate or production of an inhibitory metabolite) (Cornu et al., 2011). In the first type of models, one (for the Jameson-effect) or two inhibition functions (for the Lotka-Volterra competition model) are adjusted; the model is thus simple and can be used in many cases but may be too simple to be applicable in all cases. These models do not provide any additional information on what occurs in the product ( $\mathrm{pH}$ and biochemical changes). In the second type of models, $\mathrm{pH}$ and biochemical changes are explicitly modeled and are used to predict growth curves. These models are less parsimonious, but can be used to understand which parameters drive growth interactions and the modifications in food quality which occur during mixed fermentation. In previous articles, we proposed a model of the fermentation of gowé using a single starter culture made of lactic acid bacteria (Munanga et al., 2016) and a second model of cereal starch hydrolysis during simultaneous saccharification and lactic acid fermentation of gowé (Mestres et al, 2017). The objective of the present article is to present an overall model of the fermentation of gowé which includes the previously cited models plus a growth model of the Pichia kluyveri strain. 


\section{Material and methods}

\subsection{Raw material}

Grains of red sorghum [Sorghum bicolor, (L.) Moench], which are traditionally used to prepare gowé, were purchased on the local market in Cotonou (Benin). Malting was performed in the laboratory by steeping grains at $30{ }^{\circ} \mathrm{C}$ for $15 \mathrm{~h}$ followed by germination in an air-conditioned cabinet $\left(30{ }^{\circ} \mathrm{C}, 98 \%\right.$ relative humidity) for $72 \mathrm{~h}$ as detailed in Mestres et al. (2015). Raw sorghum and malted grains were ground in a Perten 3100 Laboratory Mill (Perten Instruments Hagersten, Sweden) equipped with a $0.5 \mathrm{~mm}$ sieve. Malted and non-malted sorghum flours were treated by gamma irradiation with 2 kGy (Ionisos Company, Danieux, France). The residual yeast population was less than $10^{2} \mathrm{CFU} / \mathrm{g}$ and the residual population of lactic acid bacteria was below the threshold of detection.

\subsection{Microbial strains}

Frozen yeast, Pichia kluyveri strain (VINIFLORA ${ }^{\circledR}$ FROOTZEN $^{\circledR}$ ), was provided by Chr. Hansen Company (Prades-le-Lez, France) and stored at $-80{ }^{\circ} \mathrm{C}$. Lactobacillus plantarum (CNCMI-3069) was provided by Ennolys (Soustons, France) as dry active bacteria stored at 4 ${ }^{\circ} \mathrm{C}$. For all experiments, dry active bacteria were inoculated directly.

\subsection{Microbiological methods}

\subsubsection{Pre-culture of yeast strain}

The P. kluyveri strain was pre-cultivated by inoculating $1 \mathrm{~g}$ of the frozen strain in $50 \mathrm{~mL}$ of malt extract medium (Biokar-diagnostics, Beauvais, France) and incubated at $30{ }^{\circ} \mathrm{C}$ for $24 \mathrm{~h}$ to reach an absorbance of 2.2 at $600 \mathrm{~nm}$ corresponding to a population of $10^{7} \mathrm{CFU} / \mathrm{mL}$.

\subsubsection{Batch cultures}

Six hundred milliliter glass double wall fermenters were used as described previously (Munanga et al., 2016); turbidity was registred using an in-line near infrared sensor and cell count calculated according a calibration curve. The detection limit was of 0.01 which corresponds to a population level of $4 \cdot 10^{5} \mathrm{CFU} / \mathrm{mL}$.

The effect of $\mathrm{pH}$ on the growth rate of $P$. kluyveri was determined by monitoring its growth rate on malt extract medium with a pH set between 2.5 and 9 at a fixed temperature of $30^{\circ} \mathrm{C}$, and the effect of temperature was determined by setting the temperature at between $2{ }^{\circ} \mathrm{C}$ and $45^{\circ} \mathrm{C}$ with a fixed $\mathrm{pH}$ of 6.5 . 
97 Culture tests were carried out with a Bioscreen C MBR (Labsystems, Helsinki, Finland), in 98 sterile microplates under controlled stirring and temperature $\left(30^{\circ} \mathrm{C}\right.$, for yeast strain and $37^{\circ} \mathrm{C}$, 99 for the LAB strain). Turbidity was measured at $600 \mathrm{~nm}$. Five replicates were performed for 100 each condition.

101 For P. kluyveri, YEPG broth buffered at pH 6 (1M phosphate buffer) was used for the 102 determination of minimum inhibitory concentration (MIC) for ethanol (added concentration 103 ranging from 0 to $8 \% \mathrm{v} / \mathrm{v}$, i.e. up to $63 \mathrm{~g} \cdot \mathrm{L}^{-1}$ ) and for lactic acid (added concentration ranging 104 from 0 to $25 \mathrm{~g} \cdot \mathrm{L}^{-1}$ ). Ks (half-velocity constant) and $\mathrm{Ki}$ (inhibition constant) for glucose were 105 determined with YEP by adding glucose from 0 to $50 \mathrm{~g} \cdot \mathrm{L}^{-1}$. The initial yeast population was of $10^{6} \mathrm{CFU} / \mathrm{mL}$.

For L. plantarum, the MIC of ethanol was determined in MRS broth with ethanol concentrations ranging from 0 to $8 \%\left(\mathrm{v} / \mathrm{v}\right.$ ) (i.e. up to $63 \mathrm{~g} \cdot \mathrm{L}^{-1}$ ). The Ks for glucose was determined with YEP by adding glucose from 0 to $50 \mathrm{~g} \cdot \mathrm{L}^{-1}$.

\subsubsection{Plate methods}

111 Samples were serial diluted ten times $(0.1 \mathrm{~mL})$ in $9 \mathrm{~g} \cdot \mathrm{L}^{-1} \mathrm{NaCl}$ water and plated on de Man 112 Rogosa and Sharpe agar (MRS) with $\mathrm{pH}$ adjusted at 6.2 for LAB and on Sabouraud 113 chloramphenicol agar medium (Biokar-diagnostics, Beauvais, France) for yeasts. MRS plates were incubated at $37^{\circ} \mathrm{C}$ for $48 \mathrm{~h}$ and Sabouraud plates were incubated at $30{ }^{\circ} \mathrm{C}$ for $48 \mathrm{~h}$ before counting.

\subsubsection{Validation tests for $P$. Kluyveri}

Validation tests were performed by monitoring batch cultures at $30^{\circ} \mathrm{C}$ with no $\mathrm{pH}$ control first on the malt extract medium then on gowé prepared at laboratory scale as previously described (Munanga et al., 2016) after inoculation at $10^{6} \mathrm{CFU} / \mathrm{mL}$. Samples were collected at hourly intervals to measure the substrate and the concentration of products and to enumerate microbial populations. plantarum

Validation tests with mixed inoculation were also performed on gowé prepared in the laboratory. The same procedure as above was used with the modifications listed in Table 1. 
$\mu_{\max }=\mu_{o p t} * \gamma(T) * \gamma(p H) * \gamma([A L]) * \gamma([E t O H]) * \gamma([$ glucose $])$

144 with $\gamma$ values between 0 and 1 .

145 The effect of temperature and $\mathrm{pH}$ on $\mu_{\max }$ was expressed using the cardinal temperature and $\mathrm{pH}$

146 model (CTPM) proposed by Rosso et al. (1995) according to Equation (3).

gowé

\begin{tabular}{|c|c|c|c|c|c|c|c|}
\hline \multirow[b]{2}{*}{ Experiment } & \multirow{2}{*}{$\begin{array}{c}\text { Pre-cooked } \\
\text { flour }(\mathrm{g})\end{array}$} & \multirow{2}{*}{$\begin{array}{c}\text { Pre-cooking } \\
\text { temperature } \\
\left({ }^{\circ} \mathrm{C}\right)\end{array}$} & \multirow{2}{*}{$\begin{array}{l}\text { Uncooked } \\
\text { flour }(\mathrm{g})\end{array}$} & \multirow{2}{*}{$\begin{array}{c}\text { Malt } \\
\text { flour } \\
(\mathrm{g})\end{array}$} & \multicolumn{2}{|c|}{ Inoculation rate $(\mathrm{CFU} / \mathrm{g})$} & \multirow{2}{*}{$\begin{array}{c}\text { Fermentation } \\
\text { temperature }\left({ }^{\circ} \mathrm{C}\right)\end{array}$} \\
\hline & & & & & $\begin{array}{c}\text { Lactobacillus } \\
\text { plantarum }\end{array}$ & $\begin{array}{l}\text { Pichia } \\
\text { kluyveri }\end{array}$ & \\
\hline V1 & 15 & 80 & 60 & 25 & $7.3 \cdot 10^{5}$ & $7.0 \cdot 10^{5}$ & 25 \\
\hline V2 & 15 & 80 & 60 & 25 & $5.4 \cdot 10^{6}$ & $1.8 \cdot 10^{4}$ & 35 \\
\hline V3 & 20 & 80 & 55 & 25 & $5.8 \cdot 10^{5}$ & $6.3 \cdot 10^{4}$ & 40 \\
\hline S1 & 30 & 85 & 45 & 25 & $5.0 \cdot 10^{5}$ & $5.0 \cdot 10^{5}$ & 40 \\
\hline S2 & 30 & 85 & 45 & 25 & $1.0 \cdot 10^{6}$ & $1.0 \cdot 10^{5}$ & 40 \\
\hline
\end{tabular}

\subsection{Chemical Analysis}

Lactic acid, glucose, maltose and ethanol contents were measured by HPLC as previously described (Munanga et al., 2016).

\subsection{Mathematical modelling}

\subsubsection{Primary and secondary models}

The logistic growth model with delay (Rosso, 1995) was used to describe microbial growth (Equation (1)).

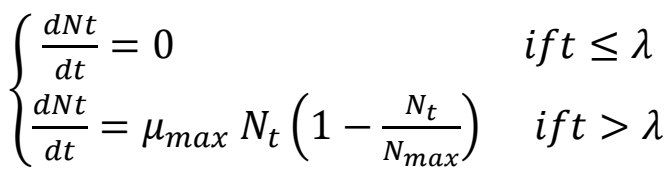

where $\mathrm{N}_{\mathrm{t}}$ and $\mathrm{N}_{\max }(\mathrm{CFU} / \mathrm{mL})$ represent the microbial population at time $\mathrm{t}$ and at the end of the growth curve, respectively, $\mu_{\max }$ the maximum growth rate $\left(\mathrm{h}^{-1}\right)$ and $\lambda$ the lag time $(\mathrm{h})$.

The gamma concept model (Zwietering et al., 1993) was used as secondary model to describe the impact of temperature (T), pH, concentrations in lactic acid ([AL]), ethanol ([EtOH]) and glucose $\left([\right.$ glucose] $)$ on maximum growth rate $\left(\mu_{\max }\right)$ (Equation $\left.(2)\right)$. 
$C M n(X)=\left\{\begin{array}{cl}0, & X \leq X_{\min } \\ \frac{\left(X-X_{\min }\right)^{n}\left(X-X_{\max }\right)}{\left(X_{o p t}-X_{\min }\right)^{n-1}\left\{\left(X_{o p t}-X_{\min }\right)\left(X-X_{o p t}\right)-\left(X-X_{\max }\right)\left[(n-1) X_{o p t}+X_{\min }-n X\right]\right\}}, & X_{\text {min }}<X<X_{\text {max }} \\ 0, & X \geq X_{\max }\end{array}\right.$

148 where $\mathrm{X}$ corresponds to environment factors ( $\mathrm{pH}$, temperature) and ' $\mathrm{n}$ ' to a shape parameter 149 that equals 2 for temperature but was adjusted for $\mathrm{pH}$.

150

\subsubsection{Modelling product formation and glucose consumption, and metabolite} interactions

153 Equation (4) was used to model the formation of ethanol (dP/dt) by P. kluyveri, where $\mathrm{Y}_{\mathrm{EtOH} / \mathrm{N}}$

154 is the yield of ethanol over P. kluyveri population and $\mu$ is the specific growth rate $\left(\mathrm{h}^{-1}\right)$ (Van 155 Impe et al., 2005):

$156 \frac{\mathrm{d}[\mathrm{EtOh}]}{\mathrm{dt}}=Y_{(E t o h / N)} * \mu N$

157 After integration, this equation gives:

$158[E t O H]=Y_{(E t o h / N)} * N$

159 The effect of the concentration of ethanol on P. kluyveri and LAB strain growth was determined 160 using Equation (6) proposed by Coroller et al. (2005):

$161 \gamma([E t O H])=1-\left(\frac{[E t O H]}{M I C}\right)^{\alpha}$

162 where $[\mathrm{EtOH}]$ represents the ethanol concentration in $\% \mathrm{v} / \mathrm{v}$, MIC the concentration of ethanol

163 for which growth is completely inhibited and $\alpha$ reflects the shape factor of the curve.

164 The MIC of lactic acid was calculated with Equation (6), the same as for ethanol.

165 Like ethanol production, glucose consumption is directly proportional to the yeast population 166 and glucose content can be modelled by Equation (7):

$$
[\text { Glucose }]=[\text { Glucose }]_{0}-Y_{(\text {glucose } / N)} * N
$$

168 where [Glucose $]_{0}$ is the intial glucose content and $Y_{(\text {glucose } N)}$, is glucose consumption in 169 relation to the yeast population.

170 In agreement with the Monod model, the gamma value for glucose was calculated according to 171 Equation (8) for LAB:

$172 \gamma\left([S]=\frac{[S]}{K_{S}+[S]}\right.$ 
173 where $[\mathrm{S}]$ is the substrate (glucose) concentration in $\mathrm{g} \cdot \mathrm{L}^{-1}$.

174 To take the inhibition of growth due to excess substrate into consideration, the model was

175 modified according to Song et al. (2008) for P. kluyveri (Equation 9):

$176 \gamma([S])=\frac{[s]}{\left\{[S]+K_{S}+\left(\frac{[S]^{2}}{K_{i}}\right)\right\}}$

180 To model mixed fermentation, we applied the global model of fermentation of lactic acid 181 bacteria and of starch hydrolysis proposed by Munanga et al. (2016) and Mestres et al. (2017), 182 and added the models of the effects of the glucose and ethanol on LAB growth and the model 183 developed for the growth of P. kluyveri. The models were implemented in Simulink 184 (Mathworks Inc., Natick, Mass, USA).

\subsection{Statistical methods}

187

\section{Results and discussion}

\subsection{P. kluyveri growth model}

The logistic model (Equation (1)) fitted the experimental data obtained for the growth of $P$. kluyveri in malt extract broth at the different temperature and $\mathrm{pH}$ conditions quite well (residual standard root mean square error, RMSE, was of $0.03 \log$ CFU), as shown in Fig. 1. The cardinal temperature and $\mathrm{pH}$ were estimated (Table 2) by adjusting the cardinal model (Equation (3)) to the experimental data sets ( $\mathrm{pH}$ ranging from 2.5 to 9.0 and temperature ranging from $2{ }^{\circ} \mathrm{C}$ to $45^{\circ} \mathrm{C}$; Fig. 2) Minimum and maximum cardinal values were determined experimentally and the value of the coefficient $\mathrm{n}$ for $\mathrm{pH}$ was set at 0.1 , as it allowed the best adjustment of the parameters of the CTPM by minimising RMSE which was of 0.04 . 
Table 2: Parameters for the growth model of P. kluyveri

\section{SD: Standard Deviation}

\begin{tabular}{|c|c|c|c|}
\hline $\begin{array}{c}\text { Modeled } \\
\text { variable }\end{array}$ & Equation & Parameter & $\begin{array}{c}\text { Value } \pm \mathrm{SD}^{*} \\
\text { (Pichia kluyveri) }\end{array}$ \\
\hline$\mu_{\max }$ & (3) & $\begin{array}{c}\mathrm{pH}_{\min } \\
\mathrm{pH}_{\max } \\
\mathrm{pH}_{\mathrm{opt}} \\
\mathrm{n}(\mathrm{pH}) \\
\mu_{\text {opt }}\left(\mathrm{h}^{-1}\right) \\
\mathrm{T}_{\min }\left({ }^{\circ} \mathrm{C}\right) \\
\mathrm{T}_{\max }\left({ }^{\circ} \mathrm{C}\right) \\
\mathrm{T}_{\text {opt }}\left({ }^{\circ} \mathrm{C}\right) \\
\lambda(\mathrm{h})\end{array}$ & $\begin{array}{c}2.4 \\
9.0 \\
4.3( \pm 0.2) \\
0.1 \\
0.73( \pm 0.03) \\
-9.2 \\
45 \\
37.6( \pm 0.6) \\
2.0(1.1)\end{array}$ \\
\hline MIC & (5) & {$[\mathrm{LA}] \mathrm{g} \cdot \mathrm{L}^{-1}$} & $30.7( \pm 1.1)$ \\
\hline MIC & (5) & {$[\mathrm{EtOH}] \% \mathrm{v} / \mathrm{v}$} & $5.1( \pm 0.3)$ \\
\hline $\begin{array}{c}\text { Ethanol } \\
\text { production rate }\end{array}$ & (4) & $\mathrm{Y}_{\text {Ethanol/N }}(\mathrm{mg} / \mathrm{CFU})$ & $4.9910^{-8}( \pm 0.13)$ \\
\hline $\begin{array}{c}\text { Glucose } \\
\text { consumption rate }\end{array}$ & & $\mathrm{Y}_{\text {glucose } / \mathrm{N}}(\mathrm{mg} / \mathrm{CFU})$ & $1.4010^{-7}( \pm 0.058)$ \\
\hline$\gamma[$ glucose $]$ & (7) & $\begin{array}{l}K_{s}\left(g \cdot L^{-1}\right) \\
K_{i}\left(g \cdot L^{-1}\right)\end{array}$ & $\begin{array}{c}0.68( \pm 0.11) \\
86( \pm 23)\end{array}$ \\
\hline
\end{tabular}

The $\mu_{\mathrm{opt}}$ calculated for P. kluyveri was $0.73 \pm 0.03 \mathrm{~h}^{-1}$ (Table 2) and the impact of $\mathrm{pH}$ on the growth rate of $P$. kluyveri was very low, between 2.5 and 6.2, as reported for other yeast strains in similar pH ranges (Betts et al., 1999; Praphailong and Fleet, 1997; Rouwenhorst et al., 1988) It should be noted that, as the yeast was pre-cultivated, lag time did not vary significantly with the growth conditions ( $\mathrm{pH}$ and temperature), its mean value was 2.0 (h).

The MIC value of lactic acid for P. kluyveri, $30.7 \mathrm{~g} \cdot \mathrm{L}^{-1}$ (Table 2), was lower than the MIC value (548 mM, i.e. $\left.49.3 \mathrm{~g} \cdot \mathrm{L}^{-1}\right)$ for a strain of Saccharomyces cerevisiae (Thomas et al., 2002).

The MIC value of ethanol for P. kluyveri, $5.03 \pm 0.02 \%\left(40 \mathrm{~g} \cdot \mathrm{L}^{-1}\right.$, Table 2$)$ was close to the values cited by Du Preez et al. (1987) (4.6-4.8 \%) for Pichia stipitis and Candida shihatae strains. A slightly lower MIC value was observed by Delgenes et al. (1988) for P. stipitis.

A sharp increase in $\mu_{\max }$ was observed (Fig. 3) with an increase in glucose concentration followed by a slight decrease of 6-7 $\mathrm{g} \cdot \mathrm{L}^{-1}$. Ks and $\mathrm{Ki}$ were adjusted to $0.68 \mathrm{~g} \cdot \mathrm{L}^{-1}$ and $86 \mathrm{~g} \cdot \mathrm{L}^{-1}$, respectively, which means that the maximum growth rate is reached with low levels of glucose and remains relatively constant below $50 \mathrm{~g} \cdot \mathrm{L}^{-1}$ of glucose.

Fig. 4 shows the relationships between the concentrations of metabolites (glucose and ethanol) and the microbial load measured in different fermentation $(\mathrm{pH}$, temperature) conditions. The ratio of glucose consumption and of ethanol production to the microbial load were independent 
of the growing conditions, at $1.4 \cdot 10^{-7} \mathrm{mg} / \mathrm{CFU}$ and $4.99 \cdot 10^{-8} \mathrm{mg} / \mathrm{CFU}$, respectively. The mass yield of ethanol from glucose $\left(\mathrm{Y}_{\mathrm{p} / \mathrm{s}}\right)$ was $0.36 \mathrm{~g} \cdot \mathrm{g}^{-1}$. This is quite low compared to the $0.51 \mathrm{~g} \cdot \mathrm{g}^{-}$

${ }^{1}$ theoretical value of glucose conversion to ethanol and to the $0.48 \mathrm{~g} \cdot \mathrm{g}^{-1}$ value observed for a Saccharomyces cerevisiae oenological strain (Lonvaud et al, 2010). No data for P. kluyveri strains have been published, however, we can mention a value of $0.26 \mathrm{~g} \cdot \mathrm{g}^{-1}$ for P. stipitis reported by Mussatto et al. (2012).

\subsection{Complementary model for LAB}

A model of LAB growth has been already developed (Munanga et al., 2016). In the case of a mixed culture, such as $P$. kluyveri and L. plantarum, the global model must take into account the impact of the glucose concentration, consumed competitively by both strains, and the impact of the ethanol produced by the yeast on the growth of the lactic strain.

A Ks value of $1.44( \pm 0.03) \mathrm{g} \cdot \mathrm{L}^{-1}$ was determined, which is it close to the values cited by Charalampopoulos et al. (2009) and Sharma and Mishra (2014) for L. plantarum, at 1.48 and $1.32 \mathrm{~g} \cdot \mathrm{L}^{-1}$, respectively. The ethanol MIC value, $6.29 \pm 0.03 \%$ (i.e. $50 \mathrm{~g} \cdot \mathrm{L}^{-1}$, with a shape factor of $2.8 \pm 0.1$ ), showed that $L$. plantarum strain displayed slightly higher tolerance to ethanol than P. kluyveri. Alegría et al. (2004) reported an even higher MIC value of ethanol (13\%) for $L$. plantarum.

\subsection{Validation of the growth model of $P$. kluyveri strain}

The global model of P. kluyveri was tested in pure culture in YEPG broth (Fig. 5) and at the manufacturing scale used for gowé (Fig. 6). In YEPG broth with no control of pH, the model fitted the experimental data for the yeast population (Fig. 5a), glucose consumption and ethanol production very well (Fig. 5b), with respective RMSE of $0.35 \log C F U, 0.20$ and $0.29 \mathrm{~g} \cdot \mathrm{L}^{-1}$. Fermentation stopped at a quite low population level $\left(4 \cdot 10^{7} \mathrm{CFU} / \mathrm{g}\right)$. The model showed this was due to the exhaustion of glucose while the maximum population in the primary model was set at a much higher level $\left(10^{10} \mathrm{CFU} / \mathrm{g}\right)$. The $\mathrm{pH}$ decreased slightly from 4.7 to 4.1 during fermentation which could be linked to the production of acetic acid by P. kluyveri. This did not significantly affect the growth of the yeast; the $\mathrm{pH}$ gamma value remained between 0.99 and 0.94 when the $\mathrm{pH}$ varied from 4.7 to 4.1 . The production of acetic acid was not taken into account in the global model because its level of production was too low to influence the final $\mathrm{pH}$ of the gowé when it was produced by a mixed (LAB and yeast) microbial population. 
253 When the mixture of sorghum flour and malt (Fig. 6a) was inoculated with P. kluyveri, the 254 evolution of the population was also well predicted by the model (RMSE of $0.23 \log \mathrm{CFU}$ ) 255 with, in particular, a final yeast population 10 times higher than that observed and predicted in 256 YEP broth. Glucose and maltose content first increased for $8 \mathrm{~h}$, as predicted by the model, 257 linked to enzymic hydrolysis of starch. Glucose consumption by yeast increased with an 258 increase in the population of $P$. kluyveri and, after $10 \mathrm{~h}$, exceeded maltose and glucose release; 259 glucose and maltose content thus began to decrease and became almost zero after $15 \mathrm{~h}$, almost 260 stopping yeast growth. The model indeed predicts residual growth ( $\mu$ max between 0.02 and $2610.03 \mathrm{~h}^{-1}$ ) promoted by the quite low but continuous release of free sugars from starch hydrolysis. 262 Ethanol production was also quite well predicted by the model (RMSE of $0.4 \mathrm{~g} \cdot \mathrm{L}^{-1}$ ); the gamma 263 value for ethanol after $10 \mathrm{~h}$ was 0.90 and did not really affect growth.

264 In parallel, changes in pH showed two phases (Figure 6b); first a decrease from 5.9 to 5.4 within $26510 \mathrm{~h}$ which could be linked to low production of acetic acid by the yeasts, followed by a sharper 266 decrease to $\mathrm{pH} 4.1$ probably linked to the growth of wild lactic bacteria present in the raw 267 material used.

\subsection{Validation of the global model on mixed fermentation}

Different gowé manufacturing conditions involving L. plantarum and P. kluyveri were used to validate the global model of gowé fermentation and to test different conditions for the preparation of gowé (Table 1). Marked variability in the process has indeed been observed (Adinsi et al., 2014; Michodejehoun et al., 2005; Vieira-Dalode et al., 2007); sorghum malt may be the only raw material used, but usually the proportion of sorghum malt is $20-25 \%$, the other raw matrial being raw sorghum or maize. In addition, one quarter (25\%) of the raw material is often pre-cooked at $70-80{ }^{\circ} \mathrm{C}$ or even $100{ }^{\circ} \mathrm{C}$. Initial LAB and yeast levels in traditional natural fermentation of gowé can vary from $10^{4}$ to $10^{6} \mathrm{CFU} / \mathrm{g}$ and from $10^{3}$ to $10^{6}$ $\mathrm{CFU} / \mathrm{g}$, respectively. Various conditions were evaluated once in order to explore the large variability in the processing conditions and to test the robustness of the model.

280 Fig. 7 shows the results of the first validation test (V1) performed in conditions close to those 281 used in traditional processing with, in particular, a fermentation temperature close to ambient 282 temperature and a similar inoculation level for both strains. The model fitted the experimental 283 data for the microbial population well (Fig. 7a; RMSE of 0.25 and $0.48 \log$ CFU for P. kluyveri 284 and L. plantarum, respectively), with only slight underestimation of the lactic population. The 
stationary growth phase began after about $22-25 \mathrm{~h}$ of fermentation. The model predicted the experimental values of $\mathrm{pH}$, lactic acid (Fig. 7b) and ethanol (Fig. 7c) contents quite well (RMSE of 0.5 and $1.9 \mathrm{~g} \cdot \mathrm{L}^{-1}$, respectively). Changes in the concentration of sugars (glucose + maltose) were roughly predicted by the model, with, in particular, an initial increase linked to dominant amylase activity, followed by a decrease linked to increasing consumption by yeasts and lactic bacteria. However, the sugar content was slightly underestimated by the model; the final concentration of sugars at the end of the experiment was between 5 and $10 \mathrm{~g} \cdot \mathrm{L}^{-1}$ while the model predicted their total consumption. Model underestimation was particularly high at the beginning of fermentation; the sugar content of the dough at zero fermentation time was indeed $45 \mathrm{~g} \cdot \mathrm{L}^{-1}$ while the value calculated from the sugar contents in malt and in raw sorghum was 15 $\mathrm{g} \cdot \mathrm{L}^{-1}$. Low soluble $\alpha$-amylase activity $(0.1 \mathrm{U} / \mathrm{g})$, naturally present in sorghum grain, cannot explain starch hydrolysis that occurred during the pre-cooking step which was performed at a temperature close to the optimum temperature for sorghum $\alpha$-amylase (Mestres et al., 2017); a contribution of insoluble amylase may be assumed. After about 22-25 h of fermentation, a pH of 4 was reached while free sugar content was low to zero; the former condition stopped the amylase activity (Mestres et al., 2017) while the latter stopped the growth of L. plantarum and $P$. kluyveri. The driving gamma value was indeed that of sugar content which was predicted to be zero after $24 \mathrm{~h}$. The other gamma values remained over 0.6 except that of $\mathrm{pH}$ for L. plantarum which dropped to 0.2 at $25 \mathrm{~h}$. At the end of the fermentation process, a safe product ( $\mathrm{pH}$ by 4.0) with non-active LAB and yeasts and low alcohol content $\left(20 \mathrm{~g} \cdot \mathrm{L}^{-1}\right)$ was obtained. However, the resulting gowé contained no sugars and will consequently not be appreciated by consumers (Adinsi et al., 2014, 2015)

Fig. 8 shows the results of the second validation test (V2) for which L. plantarum inoculation level was three hundred times greater than that of $P$. kluyveri and the fermentation temperature close to the optimum growth temperature of the two strains (Munanga et al., 2016). The model clearly (Fig. 8) overestimates the lag phase and underestimates the LAB population and lactic acid production, and consequently predicts a longer delay and a smaller drop in $\mathrm{pH}$. The model predicts a final population one log lower than the experimental value, and a very low growth rate after 13.5-14 h. The low growth rate was linked to low gamma values of $\mathrm{pH}(0.15$ at $\mathrm{pH}$ 3.9) and of undissociated lactic acid ( 0.15 at $13.5 \mathrm{~h}$ and dropping to 0 at $25 \mathrm{~h}$ ) while gamma values for glucose and ethanol were over 0.85 . In contrast to the model, the experimental data showed a high level of production of lactic acid after $15 \mathrm{~h}$ whose concentration reached more than $16 \mathrm{~g} \cdot \mathrm{L}^{-1}$ after $24 \mathrm{~h}$. This may be linked to the positive interactions between yeast and lactic 
acid bacteria that were not taken into account in the global model. Such interactions have been reported by many authors. Vitamins and co-factors accumulated and/or synthesized by yeasts which promote the growth of lactobacilli include thiamine (vitamin B1), nicotinic acid, pyridoxine (vitamin B6) and pantothenic acid (Arroyo -López et al., 2008). Gobbetti et al. (1994) showed a commensalistic relationship between yeasts and lactobacilli of leaven bread microbiota which benefited lactic bacteria, whose growth was more rapid in coculture with yeasts. For populations of yeast, the stationary phase was reached after $15 \mathrm{~h}$ whereas the model predicts continuous growth up to $25 \mathrm{~h}$. Sugar and ethanol contents were reasonably predicted by the model, although ethanol was slightly underestimated. Like in V1, the original sugar content was underestimated, but the maximum value and the decrease after $10 \mathrm{~h}$ were well predicted. It should be noted that this decrease is linked to the increasing sugar consumption by the increasing microbial load but also to the inhibition of $\alpha$-amylase at low $\mathrm{pH} ; \alpha$-amylase was predicted to be completely inhibited after $12 \mathrm{~h}$, whereas it should have stopped after $10 \mathrm{~h}$ when the $\mathrm{pH}$ reached 4 (Mestres et al., 2017). To sum up, the fermentation of gowé in the conditions in the V2 test could be stopped after 10-12 h, which would make the gowé sufficiently sour (pH $4.0)$, medium sweet $\left(55-60 \mathrm{~g} \cdot \mathrm{L}^{-1}\right)$ with low alcohol content $\left(2-3 \mathrm{~g} \cdot \mathrm{L}^{-1}\right)$.

For the V3 test, the quantity of pre-cooked flour was increased by $25 \%$, the fermentation temperature was slightly higher (but close to the $\mathrm{T}_{\mathrm{opt}}$ of both strains) to promote starch hydrolysis, and the inoculation level of L. plantarum was divided by 10 . Like for V2, the model (Fig. 9) overestimated the lag phase for LAB and consequently the beginning of the increase in lactic acid production and the decrease in $\mathrm{pH}$. The model predicted the lag phase and yeast growth reasonably well (RMSE of $0.4 \log \mathrm{CFU}$ ). The initial concentration of sugars was higher than the concentrations measured in the other tests due to the increase in the quantity of precooked flour used in this test. Like in the previous tests, the sugar content increased to a maximum (by $70-80 \mathrm{~g} \cdot \mathrm{L}^{-1}$ after $14-15 \mathrm{~h}$ ) then decreased due to the inhibition of $\alpha$-amylase as soon as $\mathrm{pH}$ dropped to below 4 . The concentration of ethanol became significant only after 10 $\mathrm{h}$ and was predicted to increase up to $20 \mathrm{~g} \cdot \mathrm{L}^{-1}$ after $25 \mathrm{~h}$. To sum up, $12 \mathrm{~h}$ of fermentation of gowé in the conditions used for the V3 test would lead to a sufficiently sour, highly sweetened product with a very low alcohol content.

347 The three validation tests provide some information about the robustness of the model. We compared experimental and calculated values (Figure 10) and calculated the RMSE for the duration of fermentation (i.e. how long it took to reach $\mathrm{pH} 4$ ), level of maltose and glucose and of ethanol at the end of fermentation. The RMSE were of $2.2 \mathrm{~h}, 15.7 \mathrm{~g} \cdot \mathrm{L}^{-1}$ and $0.9 \mathrm{~g} \cdot \mathrm{L}^{-1}$, 
respectively. The agreement between the model and the obervations for the three validations tests was thus satisfactory for the duration of fermentation and ethanol content at the end of the fermentation. The model however slightly underestimated the level of maltose and glucose for the three validation tests.

The validation tests and the model provide clear evidence that the main factors which control the fermentation and the quality of gowe are the temperature of fermentation and the level of pre-cooking. When the fermentation temperature was increased from $25{ }^{\circ} \mathrm{C}$ to $40{ }^{\circ} \mathrm{C}$, the duration of fermentation (i.e. how long it took to reach $\mathrm{pH} 4$ ) was reduced by half while the sugar content increased. The gamma temperature of $L$. plantarum indeed doubled from $25^{\circ} \mathrm{C}$ to $35-40{ }^{\circ} \mathrm{C}$, thus explaining the more rapid fermentation while the activity of $\alpha$-amylase, predicted by the model was multiplied by 4 . The bigger increase in $\alpha$-amylase activity with increasing temperature thus explained the increase in sugar content despite the acceleration of fermentation. As far as the level of pre-cooking is concerned, the model showed (results not shown) that the gelatinised part of starch was completely hydrolysed at the end of the fermentation process (90\% hydrolysis within 4-11 h) versus only 5-9\% for native starch. Even if the pre-cooking level was quite low (15 to 20\%), the hydrolysis of the gelatinised starch accounted for more than $60 \%$ of released sugars, which explains why the level of precooking has a dramatic impact on the level of sugar in fermented gowé. Another consequence is that increasing the level of malt will not have a significant impact on the sugar content of gowé. It will only affect the hydrolysis of native starch (as gelatinised starch is already completely hydrolysed with the present level of malt); for example, doubling the level of malt will only increase the level of sugar in fermented gowé by $10-15 \%$.

373 Two additional simulations were run with a fermentation temperature of $40{ }^{\circ} \mathrm{C}$ and an increased 374 level of pre-cooking ( $30 \mathrm{~g}$ pre-cooked at $\left.85^{\circ} \mathrm{C}\right)$. The amount of malt was not changed, but two 375 levels of LAB inoculum were tested. S2 simulation (Fig. 10) predicted a short fermentation 376 time $(15 \mathrm{~h})$, the highest sugar content $\left(92 \mathrm{~g} \cdot \mathrm{L}^{-1}\right)$, and a very low level of ethanol. In S1, a 377 significant proportion of sugar was indeed used by yeasts (due to the larger quantity of yeast used for inoculation) to produce ethanol. S2 fermenting conditions thus appear to be optimum to produce a safe (short fermentation period) gowé appreciated by consumers, with high sugar content. In these conditions, the sugar content will be much higher than that measured in uncontrolled gowé (25-50 g. $\mathrm{L}^{-1}$; Michodjehoun et al., 2005, Vieira-Dalodé et al., 2008). The respective inoculation levels of $\mathrm{LAB}\left(10^{6} \mathrm{CFU} / \mathrm{g}\right)$ and yeast $\left(10^{5} \mathrm{CFU} / \mathrm{g}\right)$ thus appear to be optimum to allow rapid acidification, thereby contributing to the safety of the product while 
leaving sufficient time for $\alpha$-amylase to release sugars, thereby ensuring the final product is sufficiently sweet. However, it should be noted that the validation tests were performed in a practical way, i.e. by inoculating using dry active bacteria, which explains the relatively long lag phase ( $5 \mathrm{~h}$ ) for LAB; this delay contributed to the release of sugars by $\alpha$-amylase. Using a similar inoculation level but with active living LAB, Vieira-Dalodé et al. (2008) also showed that acidification time was shorter $(7 \mathrm{~h})$ but that the resulting gowé was less sweet and not better appreciated by consumers than the traditional gowé.

\section{Conclusion}

This work is the culmination of a step-by-step modelling approach using microbial growth models from predictive microbiology to construct an overall model of gowé fermentation by integrating a model of lactic fermentation by a selected L. plantarum strain, a model of the saccharification of starch by amylase activity of the malt, and the growth model of a selected P. kluyveri strain. Even if some discrepancies remain between the model and the experimental data, particularly the experimental over-growth of LAB, the model already clarifies the processes which occur in the product and makes it possible to extrapolate rapidly in silico various fermentation conditions. It thus enables prediction of the relative hydrolysis rate of native and gelatinised starches, while their respective individual assesment would be impossible. The model showed that increasing the proportion of malt is not an efficient way to increase the quantity of sugar in gowé whereas increasing of the level of pre-cooking and hence of starch gelatinisation is. We were thus able to propose optimum processing conditions for gowé.

More generally, the builing-block model developed in this study, able to describe the growth of yeast and lactic acid bacteria, starch hydrolysis, free sugar consumption and production of ethanol and lactic acid, could be applied to many other fermented foods and particularly to nonalcoholic but acid and sweet cereal based beverages.

\section{Acknowledgments}

412 This work was supported by the European funded project, AFTER, Instituto Nacional de 413 Gestão de Bolsas de Estudo (INAGBE), Ministério do Ensino Superior of the República de 414 Angola, French Agricultural Research Centre for International Development (CIRAD) and 415 Embassy of France in Luanda (Angola). We thank Chr. Hansen Company (Prades-le-Lez, 
France) for providing Pichia kluyveri strain (VINIFLORA ${ }^{\circledR}$ FROOTZEN $^{\circledR}$ ), and Ennolys

\section{References}

420 Adinsi L., Vieira-Dalodé G., Akissoé N.H., Anihouvi V., Mestres C., Jacobs A., Dlamini N., 421 Pallet D., Hounhouigan J.D. 2014. Processing and quality attributes of gowe: a malted and 422 fermented cereal-based beverage from Benin. Food Chain, 4 (2): 171-183.

Adinsi L., Akissoé N.H., Dalodé-Vieira G., Anihouvi V., Fliedel G., Mestres C., Hounhouigan J.D.. 2015. Sensory evaluation and consumer acceptability of a beverage made from malted and fermented cereal: Case of gowe from Benin. Food Science and Nutrition, 3 (1): 1-9

426

427

428

Alegría, E., López, I., Ruiz, J.I., Sáenz, J., Fernández, E., Zarazaga, M., Dizy, M., Torres, C., and Ruiz-Larrea, F. 2004. High tolerance of wild Lactobacillus plantarum and Oenococcus oeni strains to lyophilisation and stress environmental conditions of acid $\mathrm{pH}$ and ethanol. FEMS Microbiol. Lett. 230, 53-61

Arroyo-López, F.N., Querol, A., Bautista-Gallego, J., and Garrido-Fernández, A. 2008. Role of yeasts in table olive production. Int. J. Food Microbiol. 128, 189-196.

Betts, G.D., Linton, P., and Betteridge, R.J. 1999. Food spoilage yeasts: effects of pH, $\mathrm{NaCl}$ and temperature on growth. Food Control 10, 27-33.

Blandino, A., Al-Aseeri, M. E., Pandiella, S. S., Cantero, D., \& Webb, C. 2003. Cereal based fermented foods and beverages. Food Research International, 36(6), 527-543.

Charalampopoulos, D., Vázquez, J.A., and Pandiella, S.S. 2009. Modelling and validation of Lactobacillus plantarum fermentations in cereal-based media with different sugar concentrations and buffering capacities. Biochem. Eng. J. 44, 96-105.

Cornu, M., Billoir, E., Bergis, H., Beaufort, A., and Zuliani, V. 2011. Modeling microbial competition in food: Application to the behavior of Listeria monocytogenes and lactic acid flora in pork meat products. Food Microbiol. 28, 639-647.

Coroller, L., Guerrot, V., Huchet, V., Lemarc, Y., Mafart, P., Sohier, D., and Thuault, D. 2005. Modelling the influence of single acid and mixture on bacterial growth. Int. J. Food Microbiol. 100, 167-178.

De Levie, R. 2001. How to use Excel in analytical chemistry and in general scientific data analysis (Cambridge; New York: Cambridge University Press).

Delgenes, J.P., Moletta, R., and Navarro, J.M. 1988. The ethanol tolerance of Pichia stipitis Y 7124 grown on a D-xylose, D-glucose and L-arabinose mixture. J. Ferment. Technol. 66, 417422.

Du Preez, J.C. 1994. Process parameters and environmental factors affecting d-xylose fermentation by yeasts. Enzyme Microb. Technol. 16, 944-956. 
Gobbetti, M., Corsetti, A., and Rossi, J. 1994. The sourdough microflora. Interactions between lactic acid bacteria and yeasts: metabolism of carbohydrates. Appl. Microbiol. Biotechnol. 41, $456-460$.

Lonvaud, A., Renouf, V., and Strehaiano, P. 2010. Microbiologie du vin : bases fondamentales et applications. Ed Tecdoc Lavoisier, Cachan, France.

Mestres C., Nguyen T.C., Adinsi L., Hounhouigan J.D., Fliedel G., Loiseau G. 2015. The interaction between starch hydrolysis and acidification kinetic determines the quality of a malted and fermented sorghum beverage. J. Cereal Sci., 63: 8-13.

Mestres, C., Munanga, B.J.C., Loiseau, G., Matignon, B., Grabulos, J., and Achir, N. 2017. Modeling cereal starch hydrolysis during simultaneous saccharification and lactic acid fermentation; case of a sorghum-based fermented beverage, gowé. Food Res. Int. 100, 102-111.

Michodjehoun-Mestres L., Hounhouigan J.D., Dossou J., Mestres C. 2005. Physical, chemical and microbiological changes during natural fermentation of "gowé", a sprouted or non sprouted sorghum beverage form West-Africa. African Journal of Biotechnology, 4 (6): 487-496.

Munanga, B., Loiseau, G., Grabulos, J., and Mestres, C. 2016. Modeling lactic fermentation of Gowé using Lactobacillus starter culture. Microorganisms 4, 44.

Mussatto, S.I., Machado, E.M., Carneiro, L.M., and Teixeira, J.A. 2012. Sugars metabolism and ethanol production by different yeast strains from coffee industry wastes hydrolysates. Appl. Energy 92, 763-768.

Nout MJR, Rombouts FM, Havelaar A 1989. Effect of accelerated natural lactic fermentation of infant food ingredients on some pathogenic micoorganisms. Int. J. Food Microbiol. 8: 351 361.

Nout MJR. 1991. Ecology of accelerated natural lactic fermentation of sorghum based infant food formulas. Int. J. Food Microbiol. 12: 217-224.

Praphailong, W., and Fleet, G.H. 1997. The effect of pH, sodium chloride, sucrose, sorbate and benzoate on the growth of food spoilage yeasts. Food Microbiol. 14, 459-468.

Rosso, L. 1995. Modélisation et microbiologie prévisionnelle : Élaboration d'un nouvel outil pour l'Agro-alimentaire. Université Claude Bernard-Lyon I.

Rosso, L., Lobry, J.R., Bajard, S., and Flandrois, J.P. 1995. Convenient model to describe the combined effects of Temperature and $\mathrm{pH}$ on microbial growth. Appl. Environ. Microbiol. 61, 610-616.

Rouwenhorst, R.J., Visser, L.E., Van Der Baan, A.A., Scheffers, W.A., and Van Dijken, J.P. 1988. Production, distribution, and kinetic properties of inulinase in continuous cultures of Kluyveromyces marxianus CBS 6556. Appl. Environ. Microbiol. 54, 1131-1137.

Sharma, V. and Mishra, H.N. 2014. Unstructured kinetic modeling of growth and lactic acid production by Lactobacillus plantarum NCDC 414 during fermentation of vegetable juices. LWT - Food Sci. Technol. 59, 1123-1128. 
489 Song, H., Jang, S.H., Park, J.M., and Lee, S.Y. 2008. Modeling of batch fermentation kinetics 490 for succinic acid production by Mannheimia succiniciproducens. Biochem. Eng. J. 40, 107491115.

492 Thomas, K.C., Hynes, S.H., and Ingledew, W.M. 2002. Influence of medium buffering capacity 493 on inhibition of Saccharomyces cerevisiae growth by acetic and lactic acids. Appl. Environ. 494 Microbiol. 68, 1616-1623.

495 Van Impe, J., Poschet, F., Geeraerd, A., and Vereecken, K. 2005. Towards a novel class of 496 predictive microbial growth models. Int. J. Food Microbiol. 100, 97-105.

497 Vieira-Dalode, G. Jespersen, L.Hounhouligan, J.Moller, P. L.Nago, C. M. and Jakobsen, M., 498 2007. Lactic acid bacteria and yeasts associated with gowe production from sorghum in Benin. 499 J. Applied Microbiol. 103(2): 342-349.

500 Vieira-Dalode, G., Madode, Y. E.Hounhouigan, J.Jespersen, L. and Jakobsen, M. 2008. Use of 501 starter cultures of lactic acid bacteria and yeasts as inoculum enrichment for the production of 502 gowe, a sour beverage from Benin."African Journal of Microbiology Research 2(7): 179-186.

503 Viljoen, B.C. 2006. Yeast ecological interactions. Yeast-yeast, yeast-bacteria, yeast-fungi 504 interactions and yeasts as biocontrol agents. In yeasts in food and beverages. Berlin Heidelberg 505 New York: Springer-Verlag, pp. 83-110.

506 Zwietering, M.H., Wijtzes, T., Rombouts, F.M., and Van't Riet, K. 1993. A decision support 507 system for prediction of microbial spoilage in foods. J. Ind. Microbiol. 12, 324-329. 


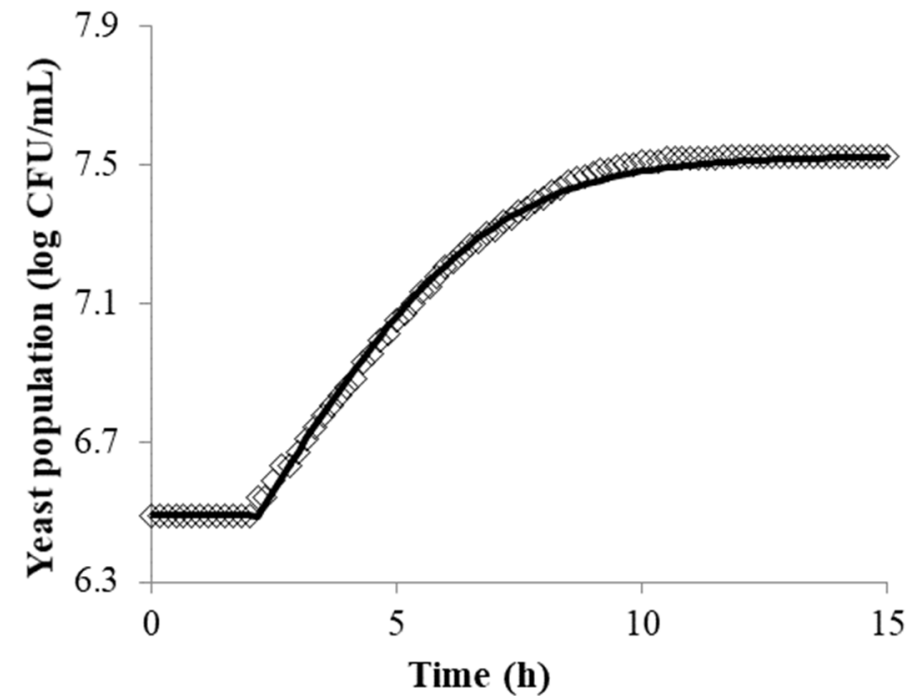

Figure 1: Growth curve of Pichia kluyveri in malt extract broth at $30{ }^{\circ} \mathrm{C}$ and $\mathrm{pH}$ 6.5. Experimental data $(\diamond)$ and predicted data (continuous line) 

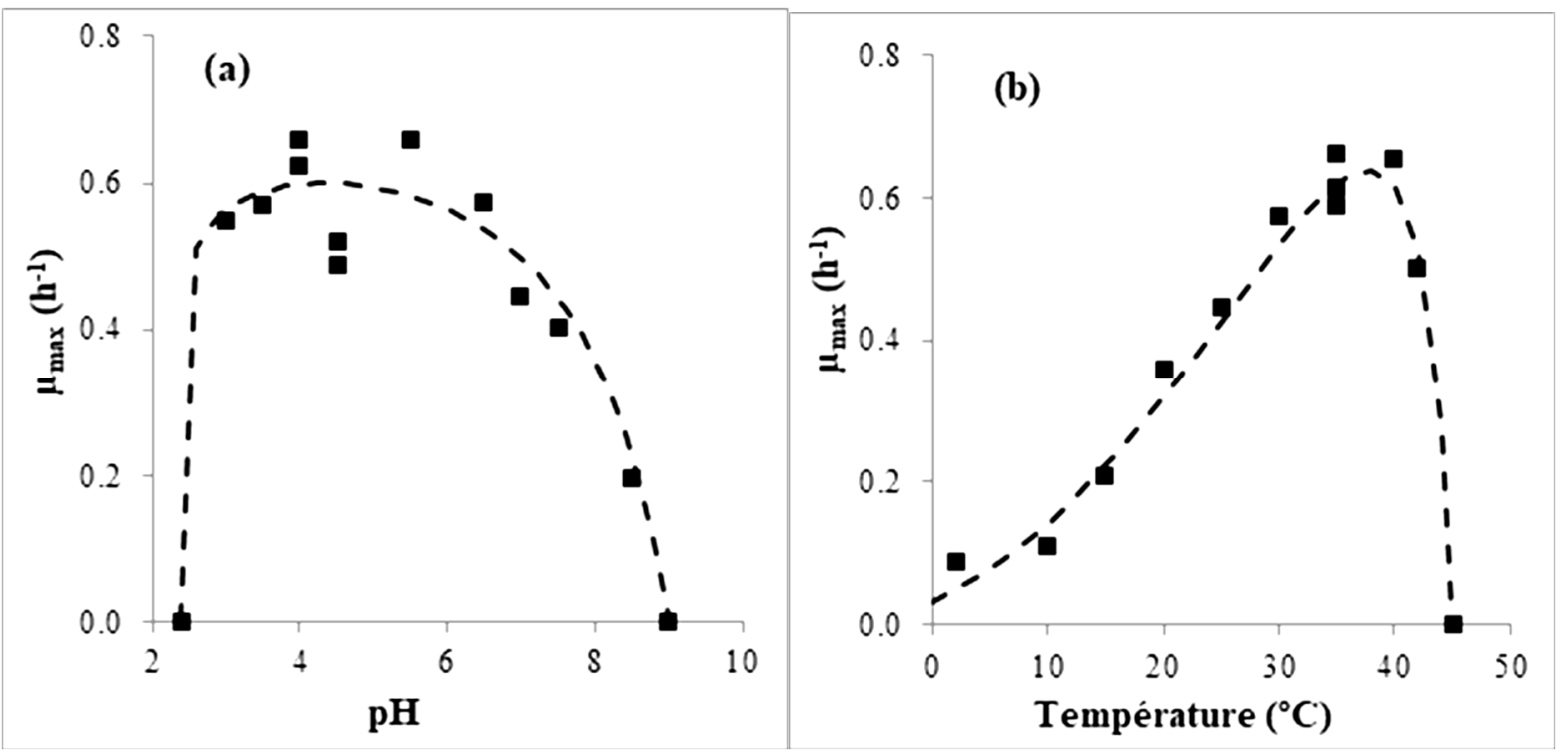

Figure 2: Effect of environment factors on growth rate of Pichia kluyveri. $\mathrm{pH}$ effect (a) and temperature effect (b). Experimental data (symbol) and predicted data (dotted line). 


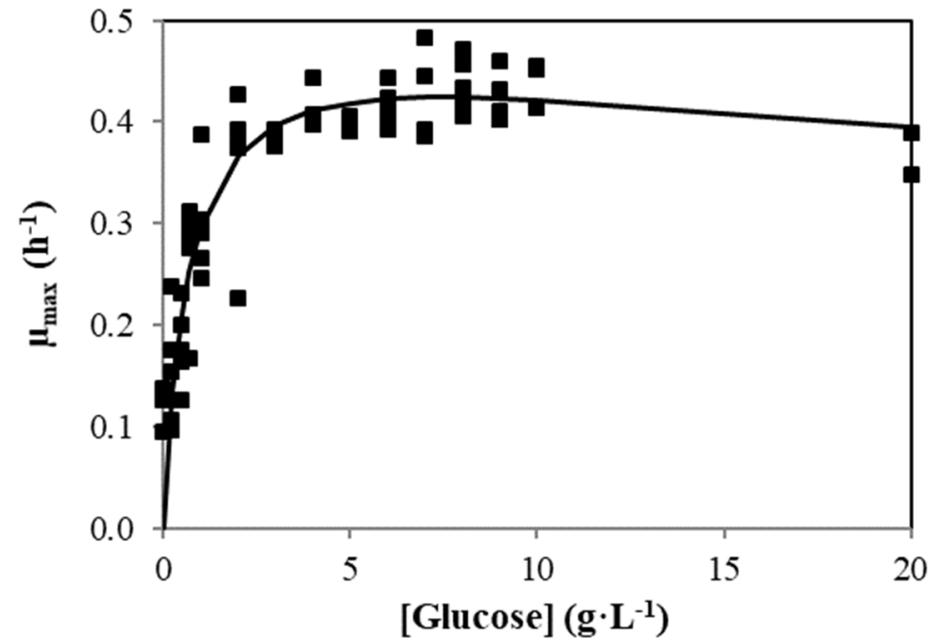

Figure 3: Effect of glucose concentration on Pichia kluyveri growth rate. Experimental data (symbol) and predicted data (dotted line). 

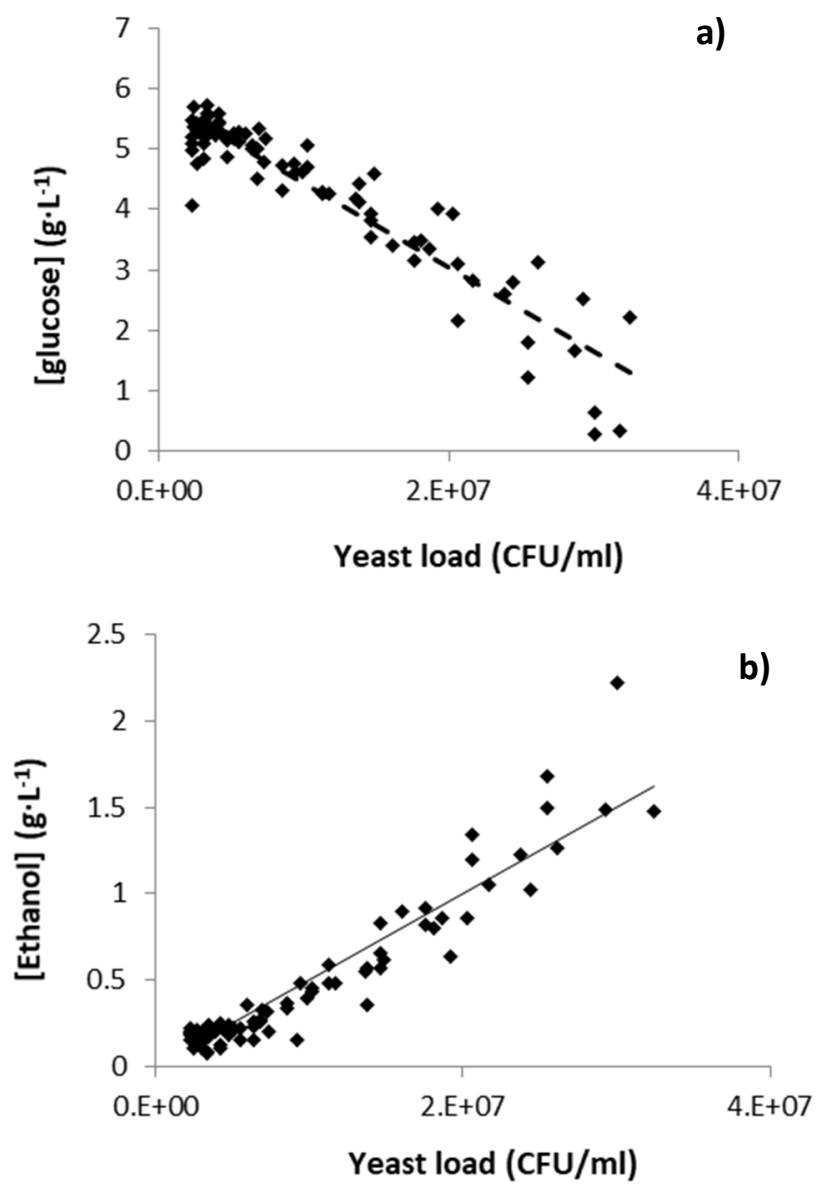

Figure 4: Regression between glucose concentration (a), ethanol concentration (b) and microbial load for Pichia kluyveri at different growth conditions of temperature and $\mathrm{pH}$. Experimental data (symbol) and predicted data (dotted line). 

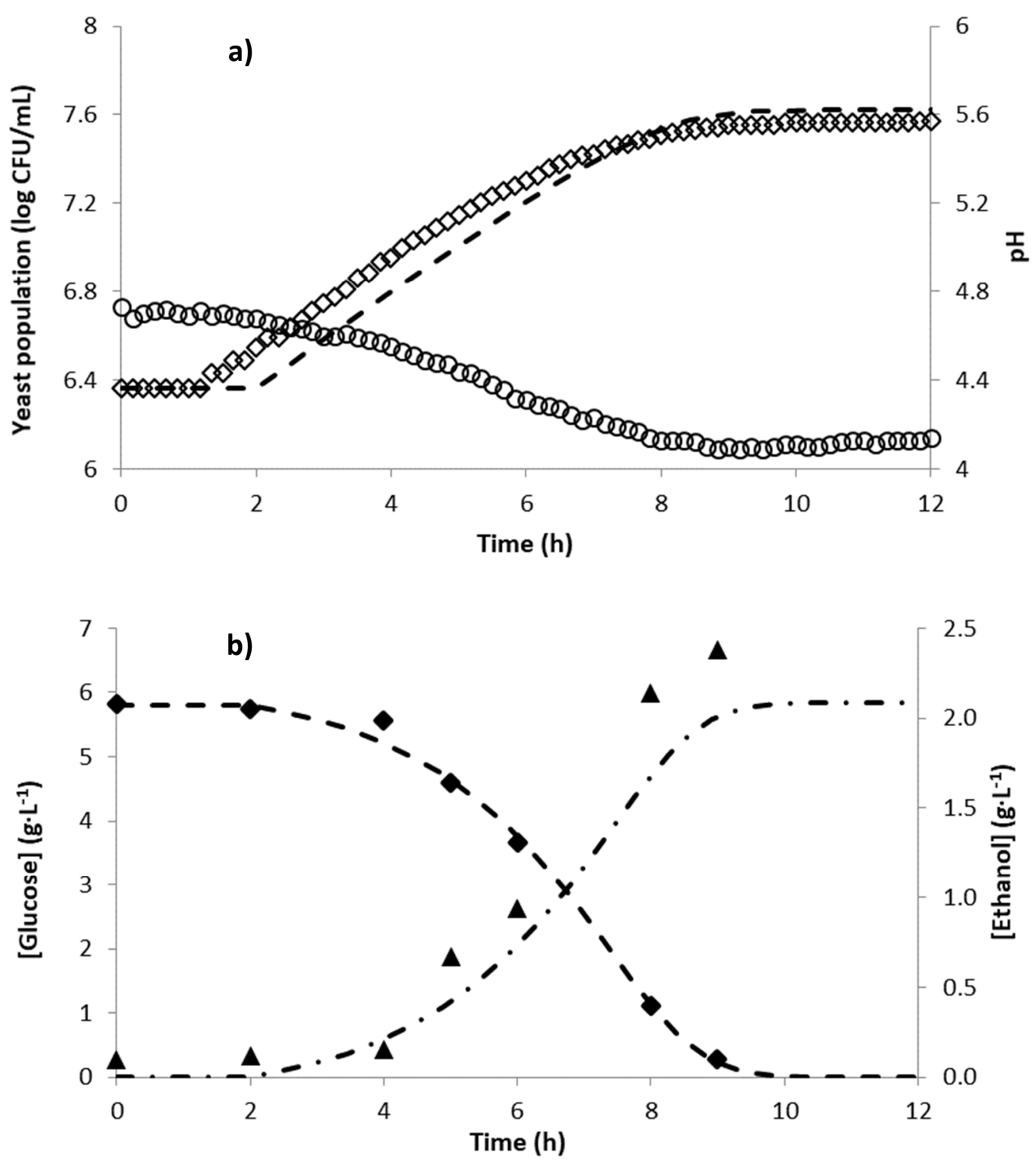

Figure 5: Changes in the yeast population $(\diamond,---)$ and $\mathrm{pH}(\mathrm{O})(\mathrm{a})$, glucose $(\diamond,--)^{-}$and ethanol $(\boldsymbol{\Delta},-$ .--) concentrations (b) for the validation test performed at $30^{\circ} \mathrm{C}$ in YPG broth inoculated with Pichia kluyveri. Experimental data (symbol) and predicted data (dashed lines) 

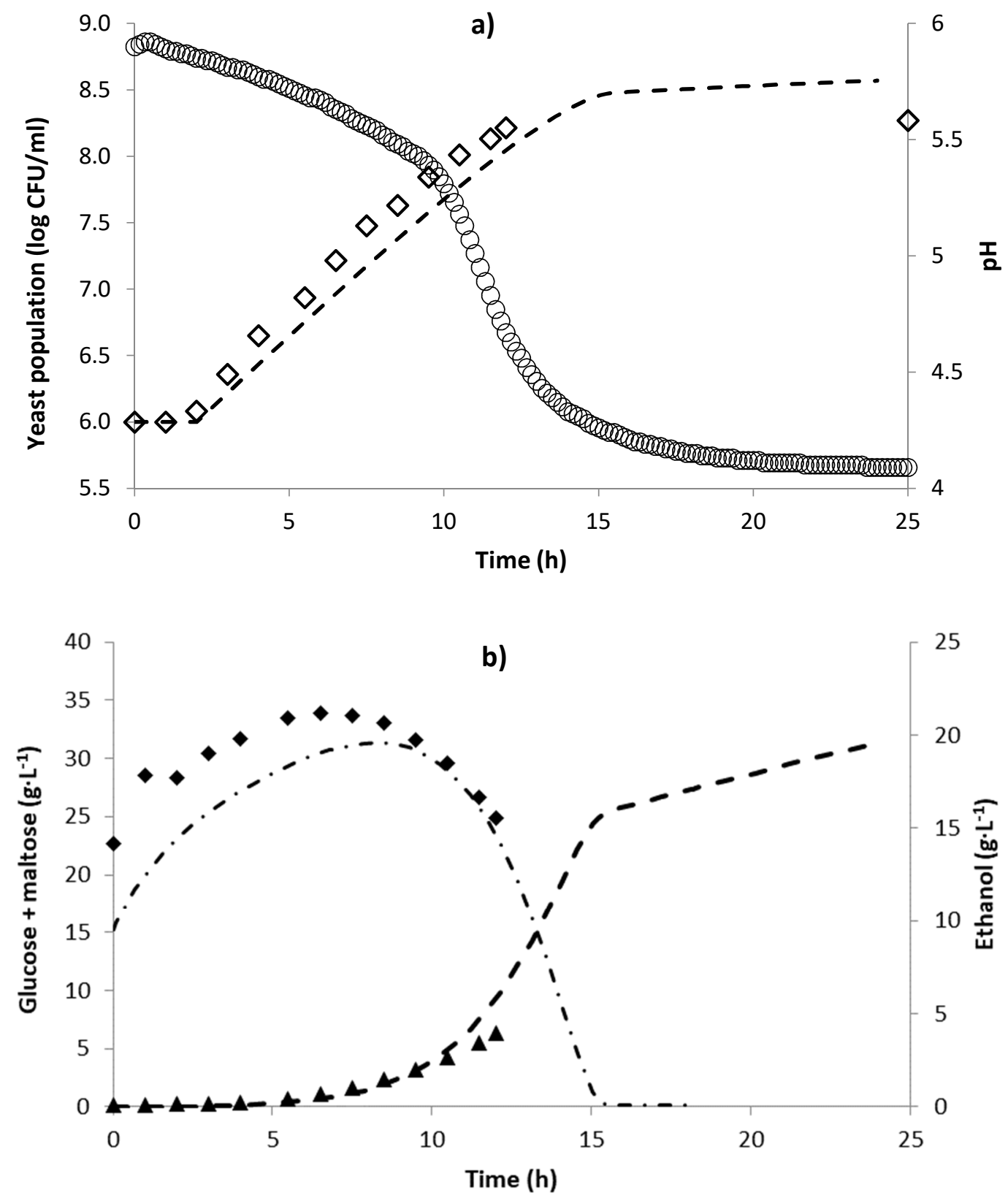

Figure 6: Changes in yeast population $(\diamond,---)$ and in $\mathrm{pH}(\mathrm{O})(\mathrm{a})$, glucose and maltose $(\diamond,-.--)$ and

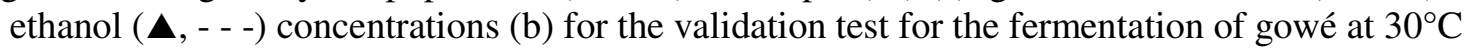
inoculated with Pichia kluyveri. Experimental data (symbol) and predicted data (dashed line) 

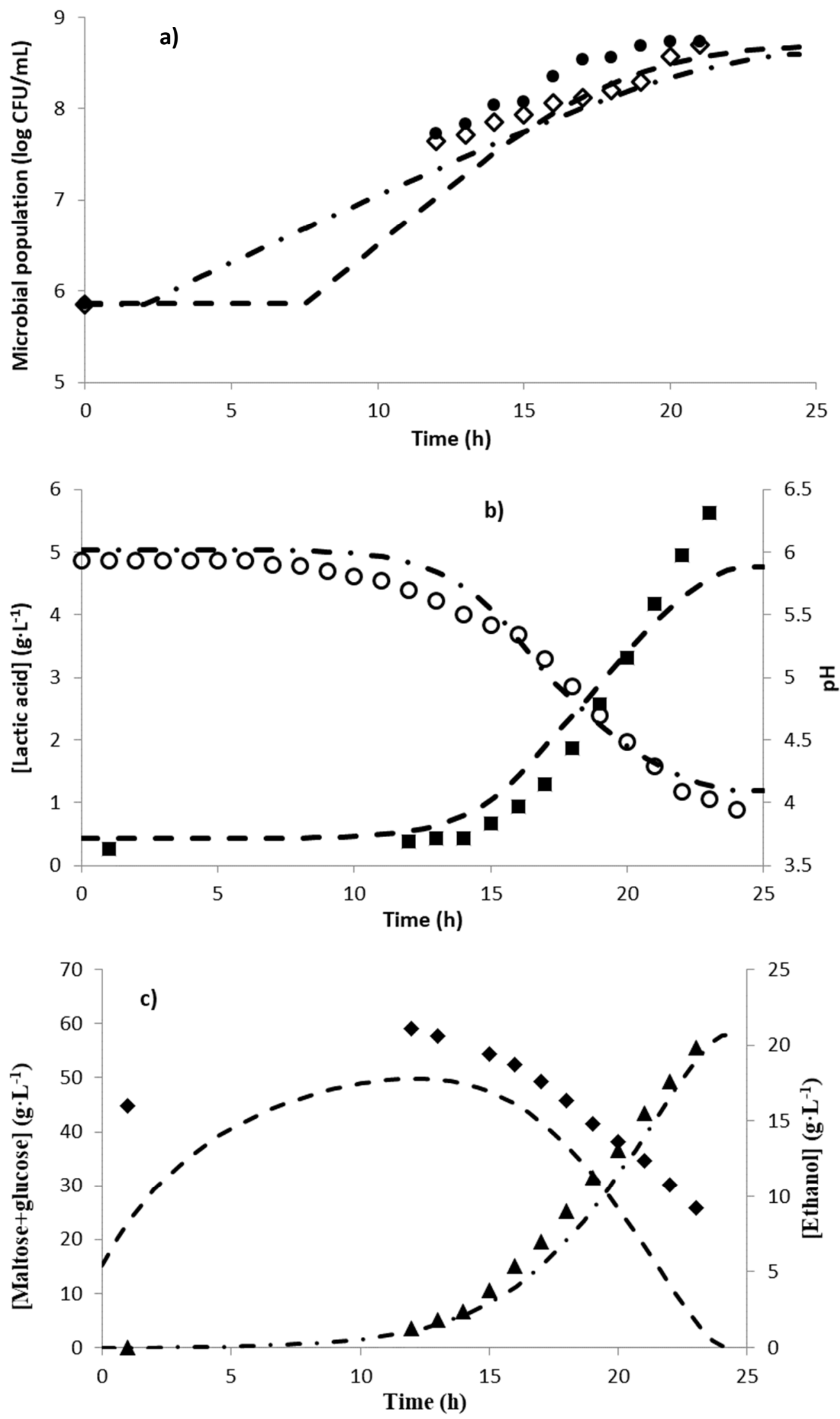

Figure 7: (a) Changes in the population of Lactobacillus plantarum $(\bullet,--)$ and Pichia kluyveri $(\diamond$, -

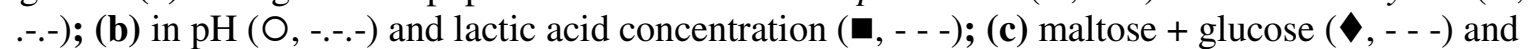
ethanol $(\boldsymbol{\Lambda},-.--$.$) concentrations for validation test V1. Experimental data (symbol), predicted values$ (dashed lines) 

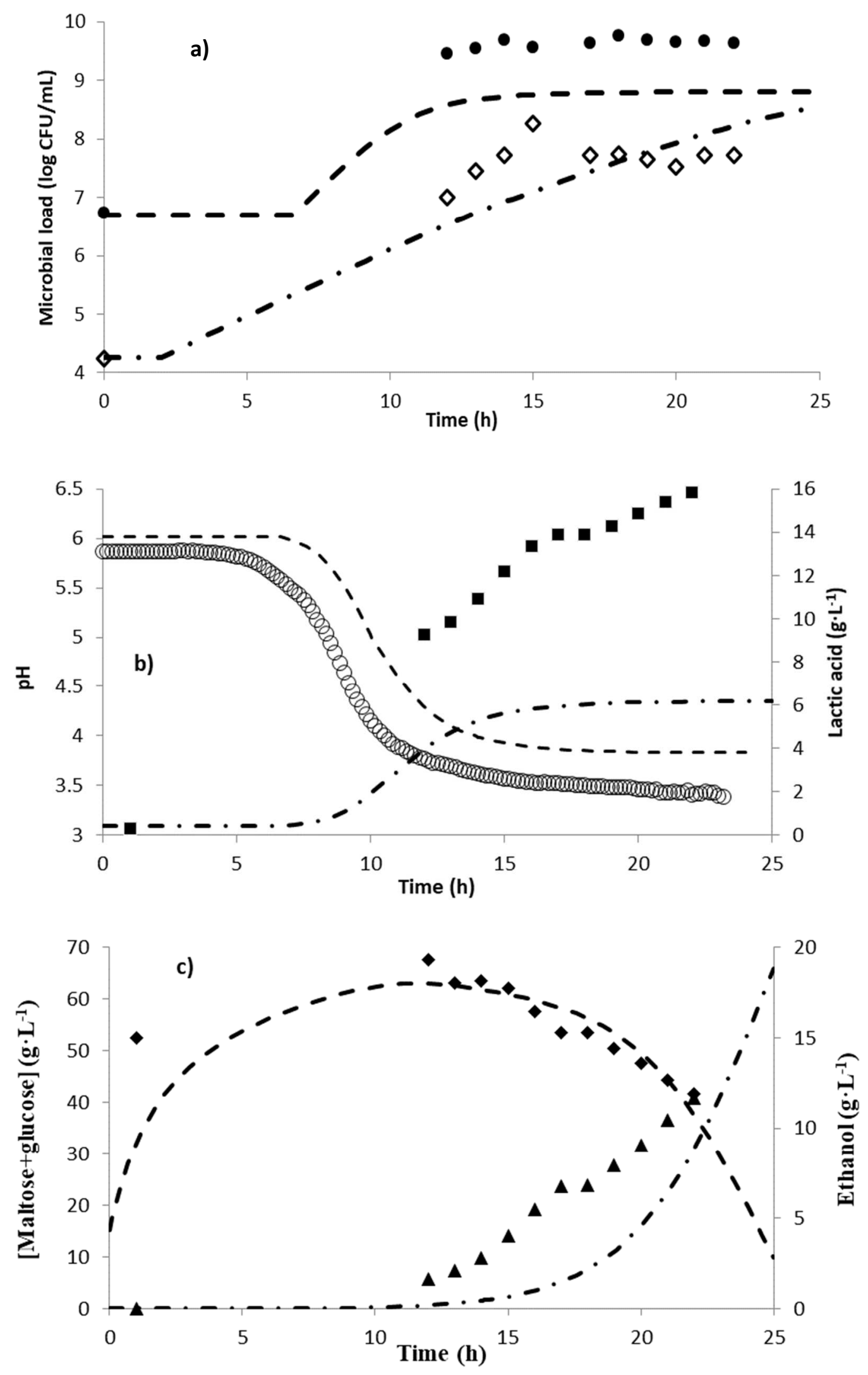

Figure 8: (a) Changes in the population of Lactobacillus plantarum $(\bullet,--)$ and Pichia kluyveri $(\diamond,-$

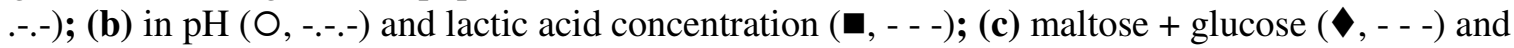
ethanol $(\boldsymbol{\Lambda},-.-.-)$ concentrations for validation test V2. Experimental data (symbol) and predicted values (dashed lines) 

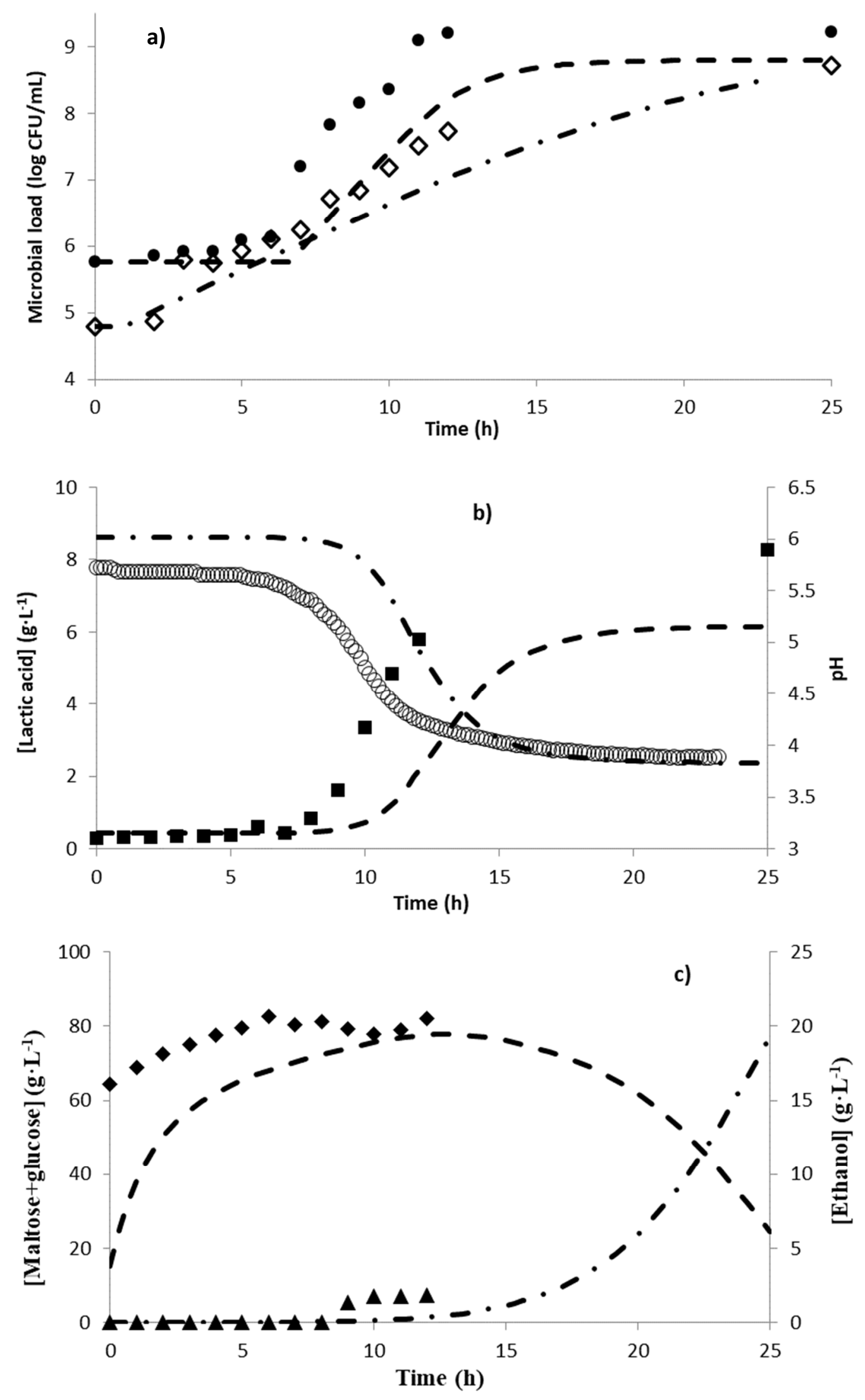

Figure 9: (a) Changes in the population of Lactobacillus plantarum $(\bullet,---)$ and Pichia kluyveri $(\diamond$, -..-); (b) in pH (O,-.-.-) and lactic acid concentration $(\mathbf{\square},-$ - - $)$; (c) maltose + glucose (४, - - -) and ethanol $(\boldsymbol{\Lambda},-.-.-)$ concentrations for validation test V3. Experimental data (symbol) and predicted values (dashed lines) 


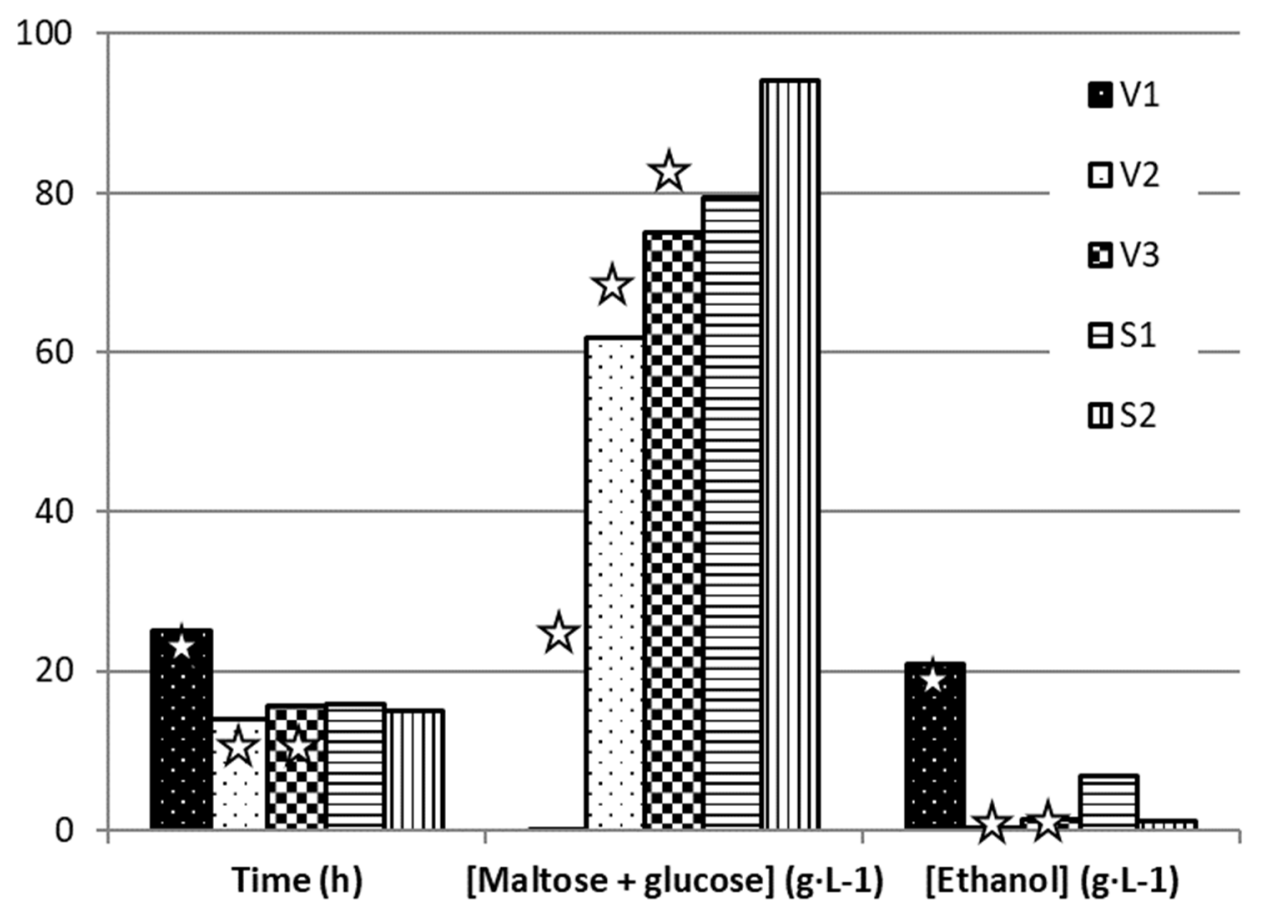

Figure 10: Predicted values of time of fermentation and of final concentrations of maltose + glucose and of lactic acid for the validation (V1-V3) and simulation tests (S1, S2). Observed values for the validation tests are positioned in the form of stars 